\title{
Flood Damage Prediction for Provincial Governments in Korea Based on Climate Change Scenarios
}

\author{
B. Park, K. Oh, and D. Lee
}

\begin{abstract}
Climate change is a major problem for Earth and its inhabitants. Thus, there is a sense of urgency to properly address climate change and its impacts. In this study, estimated damage by the years 2040 and 2090 in Korea was predicted in relation to flood damage, which is one of disasters caused by climate change. To derive each flood damage prediction, regions in Korea were classified as physical drainage systems or natural drainage systems, and important road and stream facilities were selected for analysis. Flood damage prediction was then calculated using the RCP scenarios. Based on the predictions, reduction measures for flood damage were then suggested. The analysis conducted estimated the costs of flood damage for entire areas in Korea based on RCP scenarios as ranging from $\$ 91,341,457$ to $\$ 139,983,880$ in 2040 , and from $\$ 128,011,717$ to $\$ 166,876,272$ in 2090 . In the scenarios, after flood damage levels were high in Gyeonggi Province, Gyeonsang South Province, Chungcheong North Province, and Gangwon Province (in the northern side of Korea) in 2040, and Jeolla South Province, Gyeonggi Province, and Chungcheong North Province (in the southeastern area of Korea) showed high damage levels to stream facilities. The results of this research can provide a basis for decision making for a proactive response to natural disasters caused by future climate change impacts.
\end{abstract}

Index Terms-Climate change, flood damage prediction, RCP scenario.

\section{INTRODUCTION}

One of the most threatening issues facing the human race is climate change. This is because climate change is becoming the main cause of natural disasters such as heat waves, tropical cyclones, flooding due to torrential rainfall, abnormal cold spells in winter, and heavy snow [1]. These natural disasters are predominantly caused by human activities, and the intensity and frequency of the resulting damage have been gradually increasing. As a result, social and economic damage, including human casualties, are rapidly increasing. The IPCC (Intergovernmental Panel on Climate Change) estimates that the incidence of disasters such as droughts and floods will increase owing to rises in the Earth's average temperature and precipitation levels, unless an appropriate response to climate change is rendered.

Climate change has not excluded Korea where the annual natural disaster damage has been enormous in recent years, and one of the major causes is flooding. However, the current prevention policy focuses on restoration rather than on

Manuscript received November 1, 2016; revised February 2, 2017.

B. Park and K. Oh are with the Department of Urban Planning and Engineering, Hanyang University, Seoul, Korea (e-mail: bongchur77@gmail.com, ksoh@hanyang.ac.kr).

D. Lee is with the Research Institute of Spatial Planning and Policy, Hanyang University, Seoul, Korea (e-mail: estevan0705@ hotmail.com). disaster prediction. For this reason, among the many natural disasters caused by climate change, this study focused on flood damage predictions. In this research, the strength of future flood damage was analyzed spatially considering regional characteristics. The results of this study can provide a basis for decision making in proactive responses to natural disasters caused by climate change.

\section{LITERATURE REVIEW}

Climate change refers to natural climate variability which is observed for a predetermined period, caused either directly or indirectly by human activities that alter Earth's atmospheric composition. The climate change scenario refers to predictions for the future climate (temperature, precipitation, humidity, wind, etc.), as caused by artificial changes in, for example, GHGs (Green House Gases) and aerosols.

Among climate change scenarios, the RCP scenario has the advantage of favorable resolution and reflects recent trends in changing GHG concentrations. The RCP scenarios can be classified into four types, RCP 2.6, 4.5, 6.0, and 8.5, depending on the concentration of the GHGs. First, RCP 2.6 is a scenario that assumes that human activities fall in the range of Earth's cleaning effect. Secondly, RCP 4.5 assumes that the GHG reduction policy is further progressed, while RCP 6.0 assumes that the GHG reduction policy is applied insufficiently compared with RCP 4.5. Finally, RCP 8.5 assumes that the current GHG emission levels are maintained, which is referred to as the BAU (Business As Usual) scenario (http://www.climate.go.kr/).

Studies of natural disaster damages relating to climate change focus not only on the damages but also on the vulnerability from the perspective of preemptive prevention, and on resilience from the perspective of subsequent explanations. Cutter et al. (2008) suggested an analysis framework based on vulnerability from a spatial perspective, and on resilience utilizing the estimated damage. In other words, the resilience based on the socioeconomic capability was estimated using the DROP model (Disaster Resilience of Place) [2]. Pauleit et al. (2005) investigated the correlation between land coverage changes and flood damage. The results showed that land coverage changes increased flood damage by more than 4\% [3]. Kazmierczak and Cavan (2011) used variables related to local land use and public facilities to analyze the vulnerability to flood damage considering climate change. This was based on investigating the relationship between human activities in urban areas and climate change in the United Kingdom through the IPCC's method for evaluating vulnerability [4]. Kim et al. (2011) 
derived the risk factors for urban floods, considering climate change, to analyze the intensity of flood damage in the cities of Seoul, Daejeon, Busan, etc [5].

\section{Study Method}

\section{A. Scope of Study}

The spatial scope of this study is the Republic of Korea (Fig. 1). The total land area of the Korea is $99,720 \mathrm{~km}^{2}$, and $65 \%$ of this area is mountainous. Owing to its four distinct seasons, seasonal changes in precipitation in Korea cause increasing flood damage. The scope of analysis in this study was designated using the administrative units of cities, counties, and districts (232 in total).

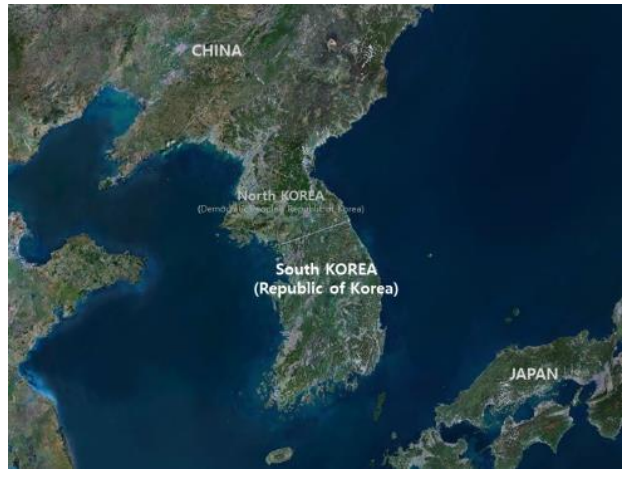

Fig. 1. The study area.

The scope of this analysis was limited to flood damage because among the damages caused by natural disasters over the past 10 years, $56 \%$ were caused by tropical cyclones, $31 \%$ by torrential rainfall, $12 \%$ by heavy snow, and $1 \%$ by gales and wind waves [6]. Tropical cyclone and torrential rainfall events predominantly occur between June and September and analysis showed that localized rainfall was a major factor in the resulting damage [7]. Additionally, analysis of the facilities affected by the flood damage, which makes up $87 \%$ of the total damage caused by all natural disasters, showed that the road facilities and stream facilities account for more than $75 \%$. For this reason, this study predominantly focused on predicting the flood damage to road and stream facilities (Fig. 2.).
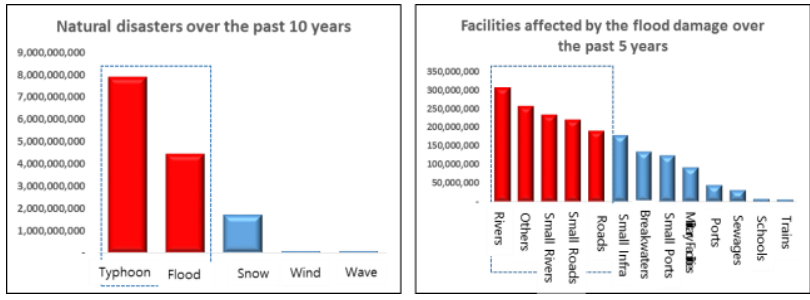

Fig. 2. The study scopes and facilities of analysis.

\section{B. Method for Predicting Flood Damage}

\section{1) Study classifications according to local characteristics}

The causes of flood damage vary depending on the local characteristics. Generally in urban areas, the possibility of flooding is high because of the high impermeability and straight strengthening of streams, unless the area is well supplied with sewerage systems. On the other hand, mountainous and agricultural areas contain natural streams, and sewerage systems are scarce. Therefore, these areas are likely to experience flood damage due to torrential rainfall. Local characteristics can be classified into physical drainage systems (urban areas), and natural drainage systems (rural areas) depending on the drainage type. In this study, Natural Breaks (Jenks) were applied to classify 232 cities, counties, and districts across Korea, according to whether they exceeded $75.2 \%$ of the supply rate of sewerage systems. As a result, there were 121 physical drainage systems and 111 natural drainage systems, which accounted for over $75.2 \%$ of the supply rate of sewerage systems (Fig. 3.).

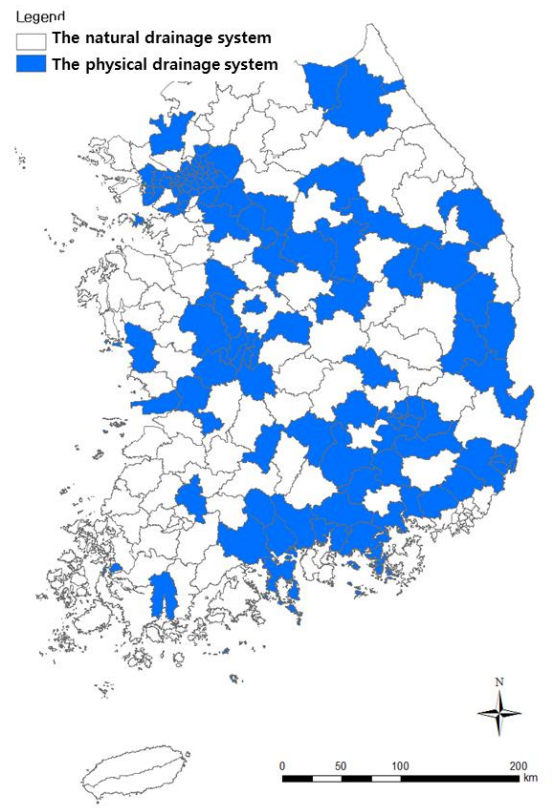

Fig. 3. The classification of study areas by local characteristics.

\section{2) The process a flood damage prediction}

For the development of the flood damage prediction, the cities, counties, and districts were classified according to the local characteristics. In other words, the flood damage prediction spatially distinguishes the physical drainage systems from the natural drainage systems for the respective road and stream facilities (Fig. 4.).

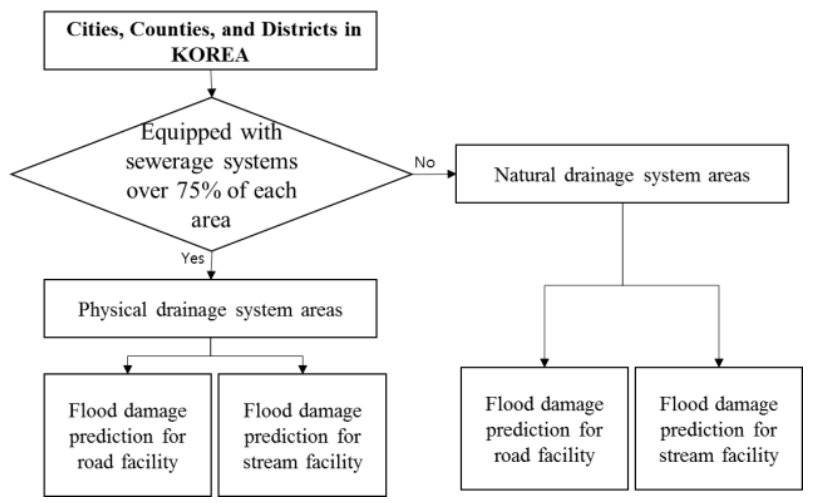

Fig. 4. Classification of flood damage prediction for considering local characteristics.

The flood damage predictions were based on the estimated flood damage over the past 30 years. First, the dependent variable was given by the flood damage to infrastructure road and stream facilities, and the independent variables included a climate factor, a natural factor, and an artificial factor which 
were selected as set out in previous studies. Next, the correlations between the variables were analyzed through multiple regression analyses to derive the major variables and to establish the quantitative flood damage prediction. By doing so, the flood damage prediction models for cities, counties, and districts classified into the physical and natural drainage systems were derived (Fig. 5.).

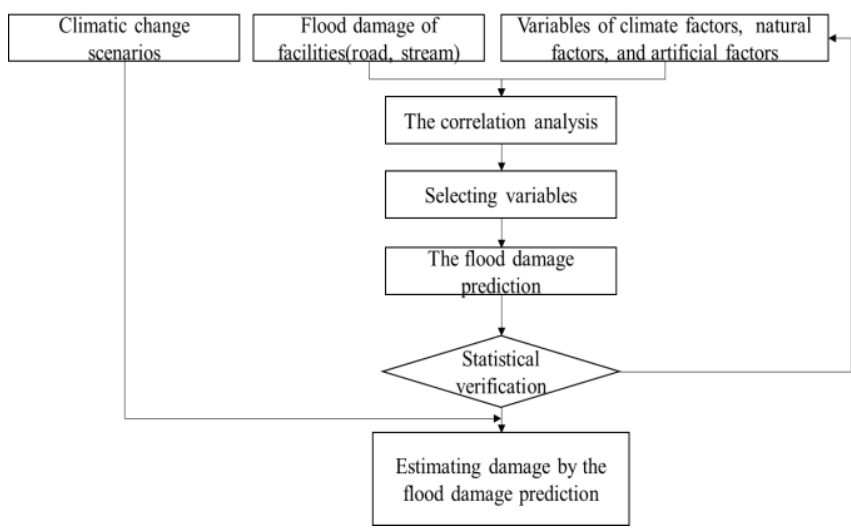

Fig. 5. The process of prediction of estimating flood damage.

\section{Selecting Preparative Variables}

The preparative variables for the response plan for flood damage are as shown in (Table I.) below. The variables were selected based on studies relating to response plans for natural disasters in Korea and throughout the world. The dependent variable is the flood damage to the road and stream facilities over the past 30 years. There were approximately 21 independent variables, classified into climate factors, natural factors and artificial factors depending on the characteristics.

\section{Flood Damage PREDiCtion}

In this study, the flood damage predictions based on the four climate change scenarios (RCP 2.6, 4.5, 6.0, 8.5) were developed to predict the estimated damage in 2040 and 2090.

\section{A. Flood Damage Prediction for Physical Drainage Systems}

The flood damage prediction model for the areas classified as physical drainage systems is as shown in (Table II). The independent variables for the road facility damage prediction model included 3-day maximum rainfall $(0.751)$, road length $(0.652)$, river improvement ratio $(-0.462)$, impermeability ratio $(0.531)$, and sewerage ratio $(-0.688)$. The stream facility damage prediction included 3-day accumulated precipitation (0.642), stream length (0.510), elevation $(-0.738)$, slope $(0.410)$, river improvement ratio $(-0.461)$, and sewerage ratio $(-0.470)$. Based on these independent variables, the flood damage predictions for the road and stream facilities in the areas classified as physical drainage systems were established. R-Squared values for the models were 0.691 and 0.724, respectively, while Durbin-Watson values were 2.006 and 2.214, respectively. Based on these results, the flood damage predictions presented in this study possesses statistical explanation power and significance.

TABLE I: THE PREPARATIVE VARIABLES

\begin{tabular}{|c|c|c|c|c|}
\hline \multicolumn{2}{|c|}{ Division } & \multicolumn{2}{|c|}{ Assessment factors } & Previous studies \\
\hline \multicolumn{2}{|c|}{ Dependent variables } & \multicolumn{2}{|c|}{ Flood damage each road and stream } & - \\
\hline \multirow{15}{*}{ Independent variables } & \multirow{5}{*}{ Climate factors } & \multicolumn{2}{|c|}{ Annual rainfall (mm) } & \multirow{5}{*}{$\begin{array}{c}{[8],[9]} \\
{[10]}\end{array}$} \\
\hline & & Day maximum & $11(\mathrm{~mm})$ & \\
\hline & & 3-day maximum & $11(\mathrm{~mm})$ & \\
\hline & & Rainfall from June $t$ & ember(mm) & \\
\hline & & Rainfall days more $\mathrm{t}$ & $0 \mathrm{~mm}$ (days) & \\
\hline & \multirow{5}{*}{ Natural factors } & \multicolumn{2}{|c|}{ Elevation(m) } & {$[8],[11]$} \\
\hline & & \multicolumn{2}{|c|}{ Slope(deg.) } & {$[8],[12]$} \\
\hline & & \multicolumn{2}{|c|}{ Stream length $(\mathrm{km})$} & [10] \\
\hline & & \multicolumn{2}{|c|}{ Forest land area $\left(\mathrm{km}^{2}\right)$} & {$[8]$} \\
\hline & & Stream density $\left(\mathrm{km} / \mathrm{km}^{2}\right)$ & Effective soil depth $((\mathrm{m})$ & [8] \\
\hline & \multirow{5}{*}{ Artificial factors } & \multicolumn{2}{|c|}{ River improvement ratio(\%) } & [9], [12] \\
\hline & & \multicolumn{2}{|c|}{ Road length $(\mathrm{km})$} & Addition \\
\hline & & \multicolumn{2}{|c|}{ Sewerage length $(\mathrm{km})$} & {$[10]$} \\
\hline & & Impermeability ratio $(\%)$ & Land use $\left(\mathrm{m}^{2}\right)$ & {$[13]$} \\
\hline & & Capacity of water pump $\left(\mathrm{m}^{3} /\right.$ minute $)$ & Sewerage ratio $(\%)$ & {$[11],[13]$} \\
\hline
\end{tabular}

\section{B. Flood Damage Prediction for Nature Drainage Systems}

The flood damage prediction model for the areas classified as natural drainage systems is shown in (Table III). The independent variables of the road facility damage prediction included 3-day maximum precipitation (0.673), elevation $(-0.420)$, forest land area $(-0.570)$, road length $(0.672)$, and impermeability ratio $(0.861)$, considering the correlation coefficient. Additionally, the independent variables for the stream facility damage prediction model included 3-day accumulated precipitation (0.678), stream length (0.432), and sewerage length (0.402). R-Squared values were 0.636 and 0.739 , respectively, while Durbin-watson values were 2.068 and 1.723 , respectively. Based on these results, the flood damage predictions for the road and stream facilities in the natural drainage systems possess statistical explanation 
power and significance.

\section{ANALYSIS RESUlts}

\section{A. Prediction Results for Cities, Counties, and Districts across Korea}

The flood damage predictions set out in this study estimated the flood damage in 2040 and 2090 for each RCP scenario, and changes in variables such as the 3-day accumulated precipitation were derived for each climate change scenario. The flood damage costs predicted by this study ranges from $\$ 91,341,457$ to $\$ 139,983,880$ in 2040 , and from $\$ 128,011,717$ to $\$ 166,876,272$ in 2090 . Physical drainage systems.

TABLE II: Flood Damage PRediction Model for Physical DRAINAGE Systems

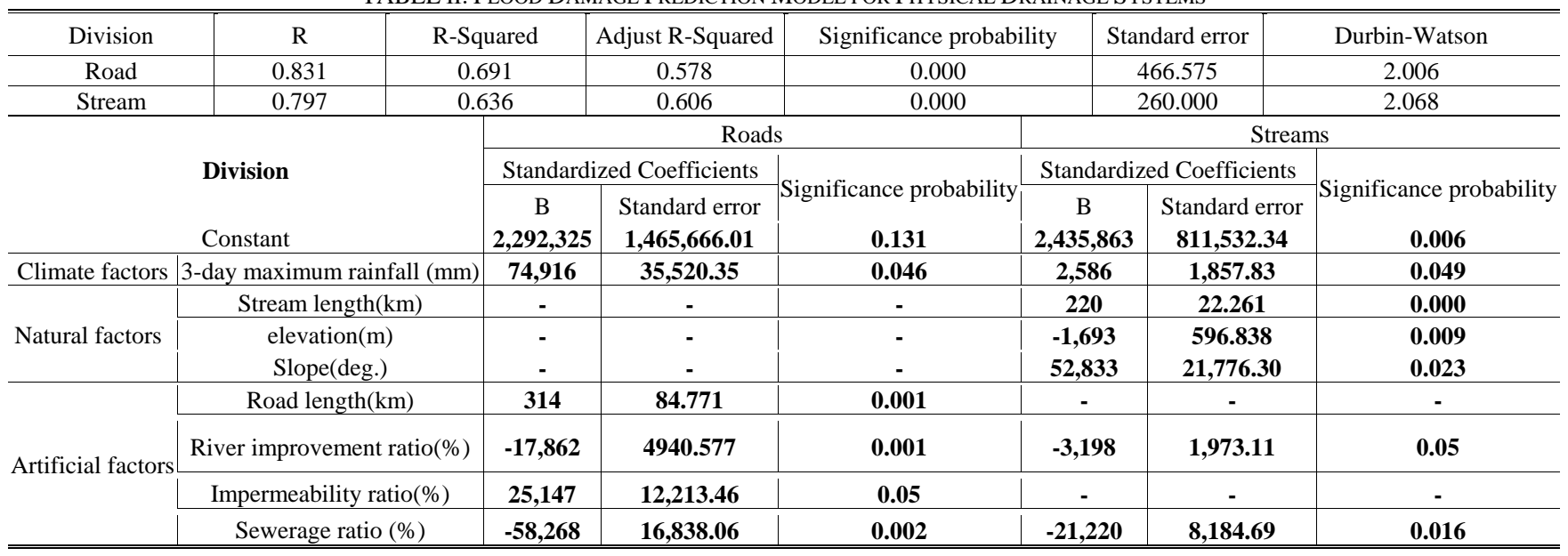

TABLE III: FlOOD DAMAGE PREDICTION MODEL FOR NATURAL DRAINAGE SYSTEMS

\begin{tabular}{|c|c|c|c|c|c|c|c|c|}
\hline Division & $\mathrm{R}$ & \multicolumn{2}{|c|}{ R-Squared } & Adjust R-Squared & \multicolumn{2}{|c|}{ Significance probability } & Standard error & Durbin-Watson \\
\hline Road & 0.797 & & 0.636 & 0.606 & & 0 & 260 & 2.068 \\
\hline Stream & 0.816 & & 0.739 & 0.717 & & 0 & 425,802 & 1.723 \\
\hline \multirow{2}{*}{\multicolumn{3}{|c|}{ Division }} & \multicolumn{2}{|c|}{ Standardized Coefficients } & \multirow{2}{*}{ Significance probability } & \multicolumn{2}{|c|}{ Standardized Coefficients } & \multirow{2}{*}{ Significance probability } \\
\hline & & & $\mathrm{B}$ & Standard error & & B & Standard error & \\
\hline \multicolumn{3}{|c|}{ Constant } & 251,612 & $244,665.68$ & 0.309 & 100,271 & $6,347,575$ & 0.876 \\
\hline \multirow{4}{*}{ Natural factors } & \multicolumn{2}{|c|}{ Stream length $(\mathrm{km})$} & - & - & - & 202 & 16.497 & 0 \\
\hline & Elevation $(\mathrm{m})$ & & -426 & 381.471 & 0.027 & - & - & - \\
\hline & Forest land area(k & & 429 & 175.995 & 0.018 & 323 & 252.394 & 0.021 \\
\hline & Stream density $(\mathrm{km} /$ & m2) & - & - & - & 218,183 & 135973.584 & 0.012 \\
\hline \multirow{3}{*}{ Artificial factors } & \multicolumn{2}{|c|}{ Road length $(\mathrm{km})$} & 183 & 24.735 & 0 & - & - & - \\
\hline & \multicolumn{2}{|c|}{ Sewerage length $(\mathrm{km})$} & - & - & - & 1.588 & 0.433 & 0.029 \\
\hline & Impermeability rati & $(\%)$ & 0.037 & 0.022 & 0.006 & - & - & - \\
\hline Road & 0.797 & & 0.636 & 0.606 & & 0 & 260 & 2.068 \\
\hline Stream & 0.816 & & 0.739 & 0.717 & & 0 & 425,802 & 1.723 \\
\hline & & & & Road & & & Stream & \\
\hline & Division & & Standardiz & ized Coefficients & Sionifiono nobilitu & Standard & d Coefficients & nrobilitis \\
\hline & & & $\mathrm{B}$ & Standard error & Significance probabillty & B & Standard error & Signilicance probability \\
\hline & Constant & & 251,612 & $244,665.68$ & 0.309 & 100,271 & $6,347,575$ & 0.876 \\
\hline Climate factors & 3-day maximum rainf & $(\mathrm{mm})$ & 1,659 & $1,354.84$ & 0.023 & 2,274 & 2,821.828 & 0.043 \\
\hline & Stream length $(\mathrm{k}$ & & - & - & - & 202 & 16.497 & 0 \\
\hline Natural factors & Elevation $(\mathrm{m})$ & & -426 & 381.471 & 0.027 & - & - & - \\
\hline & Forest land area(k & & 429 & 175.995 & 0.018 & 323 & 252.394 & 0.021 \\
\hline & Stream density $(\mathrm{km}$ & $\mathrm{m} 2)$ & - & - & - & 218,183 & 135973.584 & 0.012 \\
\hline Artificial factors & Road length(kn & & 183 & 24.735 & 0 & - & - & - \\
\hline Artincial ractors & Sewerage length( & & - & - & - & 1.588 & 0.433 & 0.029 \\
\hline & Impermeability rati & $(\%)$ & 0.037 & 0.022 & 0.006 & - & - & - \\
\hline
\end{tabular}

\section{B. Physical Drainage Systems}

The flood damage prediction results for the road and stream facilities in the physical drainage systems is as shown in (Table IV). The maximum level of damage costs to road facilities is $\$ 121,941,000$ for RCP 4.5 in 2040, and $\$ 145,993,000$ for RCP 8.5 in 2090. The trend in damage levels from the results is RCP $4.5>\mathrm{RCP} 2.6>\mathrm{RCP} 6.0>\mathrm{RC}$ $\mathrm{P} 8.5$ in 2040 . Since this is a prediction for the relatively near future, the accumulated effects of climate change are relatively small. However, in 2090, the trend in damage levels is RCP $2.6>\mathrm{RCP} 4.5>\mathrm{RCP} 6.0>\mathrm{RCP}$ 8.5. Unlike the 2040 case, the characteristics of the climate change scenarios are reflected in this result (Fig. 6.). The maximum flood 
damage costs predictions for the stream facilities are $\$ 1,859,000$ in 2040 for RCP 4.5, and $\$ 2,344,607$ in 2090 for RCP 8.5. The analysis trends for the different RCP scenarios are similar to the estimated results for road facility flood damage. However, the amount of damage to the road facilities is larger than of the stream facilities. This reflects the characteristics of the physical drainage systems which are mostly located in urban areas, and in urban areas the street ratio is high and streams are scarce.

TABLE IV: THE RESUlt OF FLOOD DAMAGE PREDICTION FOR THE ROAD AND STREAM FACILITIES IN THE PHYSICAL DRAINAGE SYSTEM

\begin{tabular}{|c|c|c|c|c|c|c|c|}
\hline \multicolumn{8}{|c|}{ Roads } \\
\hline \multicolumn{4}{|c|}{ 2040year } & \multicolumn{4}{|c|}{ 2090year } \\
\hline RCP2.6 & RCP4.5 & RCP6.0 & RCP8.5 & RCP2.6 & RCP4.5 & RCP6.0 & RCP8.5 \\
\hline $98,741,234$ & $121,941,005$ & $87,607,950$ & $75,651,604$ & $110,185,061$ & $137,148,460$ & $145,380,367$ & $145,992,891$ \\
\hline \multicolumn{8}{|c|}{ Streams } \\
\hline \multicolumn{4}{|c|}{ 2040year } & \multicolumn{4}{|c|}{ 2090year } \\
\hline RCP2.6 & RCP4.5 & RCP6.0 & RCP8.5 & RCP2.6 & RCP4.5 & RCP6.0 & RCP8.5 \\
\hline $1,765,947$ & $1,858,881$ & $1,665,223$ & $1,531,431$ & $1,829,057$ & $1,998,032$ & $2,067,711$ & $2,344,607$ \\
\hline
\end{tabular}

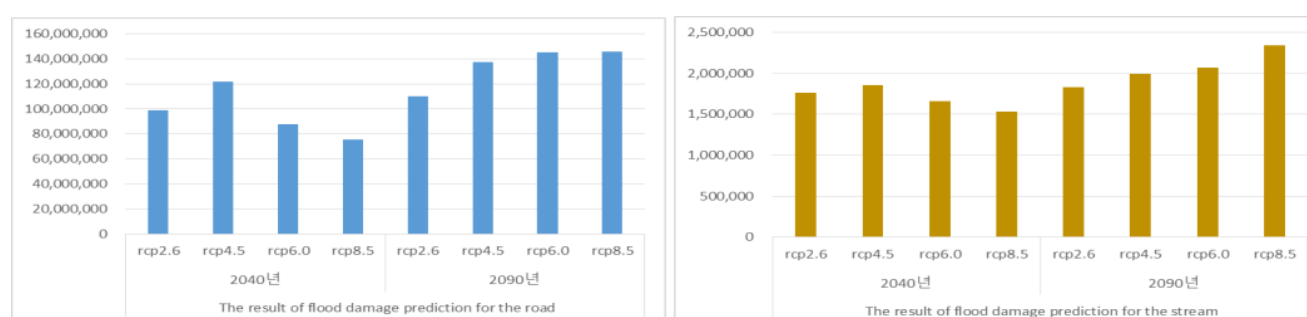

Fig. 6. The result of flood damage prediction for the road and stream facilities in the physical drainage system.

TABLE V: THE RESULT OF FLOOD DAMAGE PREDICTION FOR THE ROAD AND STREAM FACILITIES IN THE NATURAL DRAINAGE SYSTEM

\begin{tabular}{|c|c|c|c|c|c|c|c|}
\hline \multicolumn{8}{|c|}{ Roads } \\
\hline \multicolumn{4}{|c|}{ 2040year } & \multicolumn{4}{|c|}{ 2090year } \\
\hline RCP2.6 & RCP4.5 & RCP6.0 & RCP8.5 & RCP2.6 & RCP4.5 & RCP6.0 & RCP8.5 \\
\hline $1,379,089$ & $1,776,759$ & $1,386,795$ & 991,170 & $1,700,894$ & $1,883,164$ & $2,231,879$ & $2,751,810$ \\
\hline \multicolumn{8}{|c|}{ Streams } \\
\hline \multicolumn{4}{|c|}{ 2040year } & \multicolumn{4}{|c|}{ 2090year } \\
\hline RCP2.6 & RCP4.5 & RCP6.0 & RCP8.5 & RCP2.6 & RCP4.5 & RCP6.0 & RCP8.5 \\
\hline $13,826,913$ & $14,407,235$ & $13,816,626$ & $13,167,252$ & $14,296,706$ & $14,560,855$ & $15,044,437$ & $15,786,965$ \\
\hline
\end{tabular}

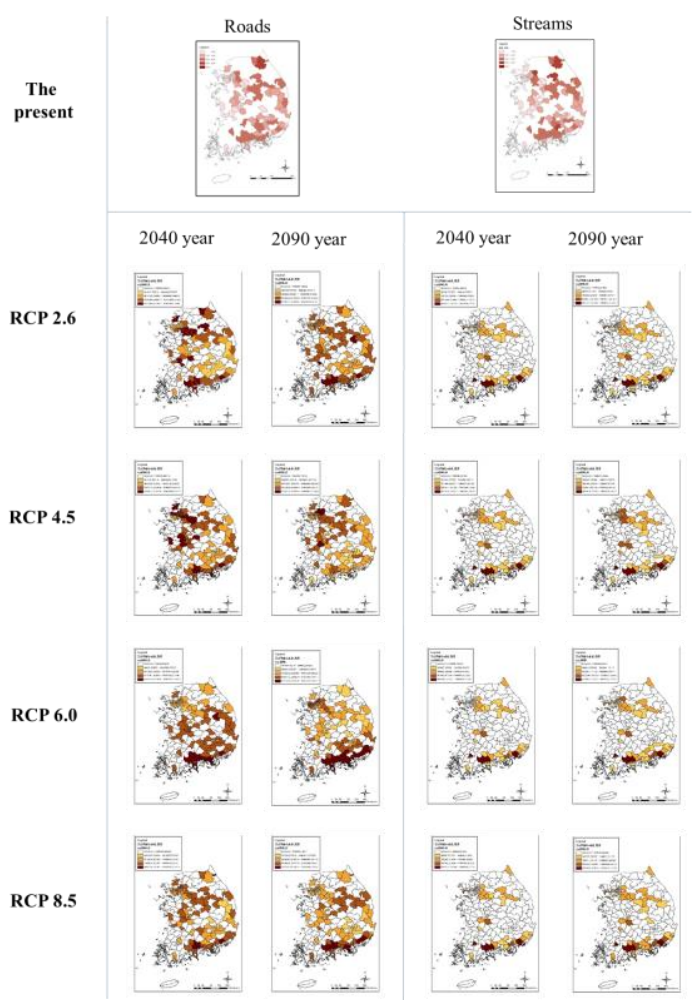

Fig. 7. The regional result of flood damage prediction for the road and stream facilities in the physical drainage system.

Fig. 7 shows the analysis results for local flood damage levels in 2040 and in 2090, based on the flood damage predictions for the road and stream facilities of the physical drainage systems. In case of road facilities, damage levels are high in Gyeonggi Province, Gyeonsang South Province, Chungcheong North Province, and Gangwon Province (in the northern area of Korea) in 2040, while Jeolla South Province, Gyeonggi Province, and Chungcheong North Province (in the southeastern area in Korea) shows high damage levels for stream facilities. Specifically, the higher damage levels were expected in the physical drainage system zones where the population levels and the distribution of sewerage facilities are relatively low.

\section{Natural Drainage Systems}

The flood damage prediction results for the road and stream facilities in the natural drainage systems is shown in (Table V). The results for road facilities show that the maximum damages were $\$ 1,777,000$ in 2040 for RCP 4.5, and $\$ 2,752,000$ in 2090 for RCP 8.5. The results for the stream facilities show that the maximum damages are $\$ 14,407,000$ in 2040 for RCP 4.5, and \$2,345,000 in 2090 for RCP 8.5. The trends for each scenario were influenced in the same way as for the physical drainage systems. However, the amount of damage to the stream facilities is greater, unlike the physical drainage system case. This reflects the characteristics of natural drainage systems which make-up the majority of the rural areas. Owing to low urbanization, the street ratio is low while many streams are naturally developed (Fig. 8.). 


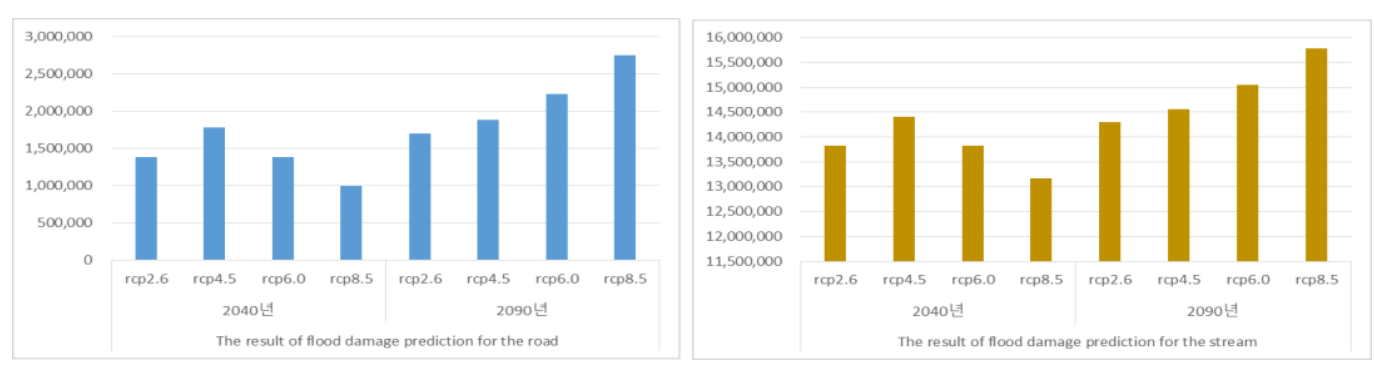

Fig. 8. The result of flood damage prediction for the road and stream facilities in the natural drainage system.

Fig. 9 compares regional intensities of flood damage in 2040 and 2090 based on the flood damage predictions for the road and stream facilities in the natural drainage systems. High levels of damage are found in Gyeonggi Province, and Gangwon Province (in the northern area in Korea) in 2040, while Gyeonggi Province and Jeolla South Province (in the western part of KOREA) suffered severe damage in 2090. In the areas classified as natural drainage systems, damage levels are relatively high as these areas are near streams and mountains. Additionally, damage levels are high as the distribution of sewerage is relatively low.

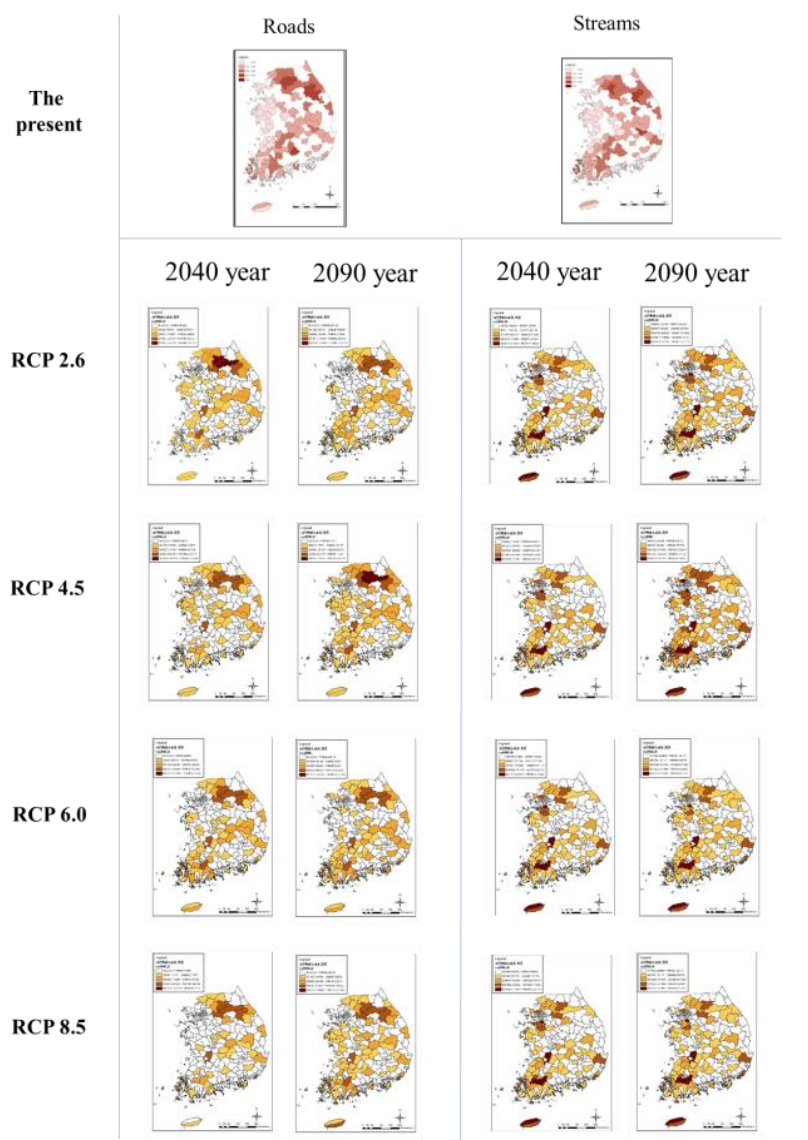

Fig. 9. The regional result of flood damage prediction for the road and stream facilities in the natural drainage system.

\section{Results of Analysis}

This study spatially classified the estimated flood damage in 2040 and 2090 into physical and natural drainage systems, and established flood damage predictions for the respective road and stream facilities. In physical drainage system areas, damage to road facilities was larger than for stream facilities. The natural drainage system area was found to have the opposite effect.

This trend continued into 2040 and 2090. In the results of the analysis of the climate change scenarios, the flood damage of RCP 8.5 was the greatest increase in road facilities, and RCP 6.0 and 8.5 were similar trends in stream facilities.

\section{RESUlTS AND DisCUSSION}

In this study, flood damage was selected among natural disasters due to climate changes to establish a prediction model based on RCP scenarios in order to estimate the flood damage costs in 2040 and 2090. Local characteristics were reflected by classifying local areas into physical and natural drainage systems. Additionally, road and stream facilities were selected from the various facilities within each drainage system to derive the flood damage predictions and to investigate the models' statistical explanation power and statistical significance through verification. As a result of the analysis, it was predicted that the amount of flood damage will continue to increase. This trend continues into 2040 and 2090.

A limitation of this study is that it does not calculate multilateral damage costs other than the damage to the road and stream facilities. Current legislative and institutional discussions have suggested no practical plans to reduce flood damage. Additionally, since the analysis was conducted for the administration units of cities, counties, and districts, further microscopic predictions and countermeasures could not be provided.

Nonetheless, the flood damage predictions and the verification of reduction measures presented in this study can provide a meaningful basis for reducing flood damage because in the case of flood damage, the interaction of factors such as casualties, property losses, cultivation losses, and landslides, as well as the restoration costs of facilities, should be seriously considered. Also, the reduction measures for flood damage should be selected through an economic feasibility analysis based on the effects. In other words, by considering the sensitivity of the major factors, the economic effects were determined as was the factor which provides the greatest decrement of damage selection. This analysis can be used as a practical applications in current medium- and long-term policies.

Finally, this study can suggest a countermeasure for reducing flood damage, and thus, the results of this study can be used for making decisions regarding preemptive flood damage reduction measures.

\section{ACKNOWLEDGMENTS}

This work was supported by the Development of Economic Assessment Technique for Climate Change Impact and Adaptation Considering Uncertainties (Korea Ministry 
of Environment, Project No. 2014001310010)

\section{REFERENCES}

[1] IPCC, "Summary for policymakers," Climate Change 2014: Impacts, Adaption and Vulnerability, 2014.

[2] S. L. Cutter, L. M. Barnes, C. Burton, E. Evans, E. Tate, and J. Webb, "A palace-based model for understanding community resilience to natural disasters," Cobal Environmental Change, vol. 18, no. 4, pp. 598-606, 2008.

[3] S. Pauleit, R. Ennos, and Y. Golding, "Modeling the environmental impacts of urban land use and land cover change - A study in Merseyside UK," Landscape and Urban Planning, vol. 71, no. 2-4, pp. 295-310, 2005.

[4] A. Kazmierczak and G. Cavan, "Surface water flooding risk to urban communities: Analysis of vulnerability, hazard and exposure," Landscape and Urban Planning, vol. 103, no. 2, pp. 185-197, 2011.

[5] B. K. Kim, D. W. Jang, N. Jang, and D. M. Yang, "The deduction of urban flood risk factor considering climate change," Journal of Safety and Crisis Management, vol. 7, no. 1, pp. 125-142, 2011.

[6] National Emergency Management Agency, "Disaster year book," 2014.

[7] J. H. Jung, H. W. Kim, D. G. Kim, J. Y. Won, J. E. Park, and J. H. Park, "Impact analysis of social disaster and cost estimation of the damage," National Disaster Management Institute, 2014.

[8] D. R. Lee, J. W. Moon, J. H. Kim, and S. G. Kang, "Analysis of relationship between physical characteristics in watershed and tank model parameters," Korean Society of Civil Engineers, pp. 3537-3539, 2008.

[9] T. S. Park, K. M. Kim, Y. S. Yoon, and S. B. Lee, "Analysis of flood damage characteristics and development of flood damage index," Korea Research Institute for Human Settlements, pp. 59-79, 2005.

[10] C. H. Lee, "Analysis of flood damage characteristics and development of flood damage index," Seoul Development Institute, pp. 57-86, 2006

[11] H. M. Kim., D. G. Lee, and C. Park, "A study on selection for vulnerable area of urban flooding adaptable capacity using MaxEnt in Seoul," Korea Planning Association, Journal of Korea Planning Association, vol. 48, no. 4, pp. 205-217, 2013.

[12] D. H. Bea, I. W. Jung, and H. J. Han, "Climate change impact assessment and adaptation strategy on water resources in the Han River basin," Gyeonggi Research Institute, pp. 96-113, 2007.

[13] S. Y. Sin, S. M. Lee, and M. G. Park, "Strategies to prevent flooding in response to weather extremes," Seoul Development Institute, pp. 8-16, 2011.

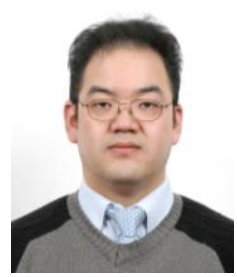

B. C. Park is a Ph. D. candidate in the Department of Urban Planning at Hanyang University in Seoul, Korea. He received his master's degree in urban planning at Hanyang University for research on improving the land suitability assessment system II. $\mathrm{He}$ is currently a researcher of the national R\&D project, developing the urban thermal environmental planning and design system for adapting climate change. His research interests include urban environmental planning, landscape ecology, GIS and spatial analysis, and climate change adaptation.

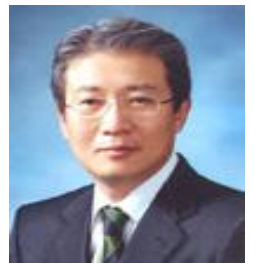

K. S. Oh is a professor in the Department of Urban Planning and Engineering at Hanyang University in Seoul, Korea, where he conducts courses on environmental planning, urban design, landscape analysis, GIS and urban spatial analysis, and climate change adaptation. $\mathrm{He}$ completed both his undergraduate and graduate work in landscape architecture at Seoul National University and Cornel University, respectively. He received his Ph.D. in environmental planning at the University of California, Berkeley. Professor Oh was a visiting professor for the Center for Advanced Spatial Analysis at the University College London, U.K. His recent works involve investigating the carrying capacity of the urban environment and assessment systems. $\mathrm{He}$ is also developing planning approaches to ubiquitous and smart cities. Prof. Oh is currently the principal investigator of a national $\mathrm{R} \& \mathrm{D}$ project, developing the urban thermal environmental planning and design system for adapting climate changes.

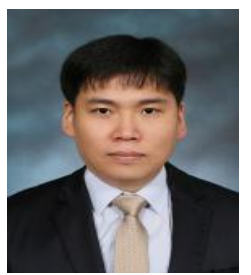

D. W. Lee is a post-doctoral researcher at the Research Institute of Spatial Planning \& Policy, Hanyang University, Seoul, Korea. He received his doctorate degree in Urban Planning at Hanyang University for his research, flood mitigation capability of urban green infrastructures. Mr. Lee is currently a researcher of the national $\mathrm{R} \& \mathrm{D}$ project, developing the urban thermal environmental planning and design system for adapting climate change. His research interests include urban environmental planning, landscape ecology, GIS and spatial analysis, and climate change adaptation. 